\title{
Drug Utilization Pattern in Cardiovascular Diseases: A Descriptive Study in Tertiary Care Settings in Pakistan
}

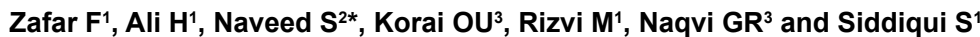 \\ ${ }^{1}$ Faculty of Pharmacy, Ziauddin University Karachi, Pakistan \\ ${ }^{2}$ Jinnah University for Women, Pakistan \\ ${ }^{3}$ Federal Urdu University of Arts, Science and Technology, Pakistan
}

\begin{abstract}
The correct use of cardiovascular drugs in patients has been shown to decrease the risk associated with cardiovascular morbidity and mortality. The objective of this study was to determine the drug utilization pattern in cardiovascular diseases. For this purpose we conducted this study in various tertiary care setups located in various areas of Karachi, from January to March, 2014. We collected the data from 100 patients having different age groups. The collected data was assessed to determine the prescribing trends. Results indicated that hypertension and ischemic heart diseases were mostly diagnosed and mostly diseases were treated by giving the drugs in combinations. The use of Beta Blockers, Diuretics, Calcium Channel Blockers and Angiotensin Converting Enzymes (ACE) inhibitors was very common. Also prescribing errors related to dosing frequency and prescribed dose were also determined. Results were analyzed with SPSS 20 using Chi square model to calculate the study outcome. Furthermore standard error and statistical variance for the given data is also calculated by descriptive analytical procedure. Present study will help the health practitioners to optimize the appropriate use of cardiovascular drugs.
\end{abstract}

Keywords: Drug Utilization, Hypertension, Ischemic heart diseases, Prescribing errors and health practitioners.

\section{Introduction}

During past few years numerous research studies have been conducted worldwide to determine the safe and effective drug utilization indicating that inappropriate drug use is a universal phenomenon [1]. Trend of drug utilization studies is raised globally in different health setups to examine the use of drugs in a society. This results in enormous social, economic and medical significance. Such type of drug utilization assessments is helpful to determine the prescribing patterns and to set the priorities to avoid the irrational drug use [2].

It has been reported that drug treatment is likely to be effective only when patients are informed well about the therapy [3]. Recognition of the prescribing problems is one of the most fundamental steps towards improving the prescribing quality and medication safety. Both features required rational medication prescribing and inappropriate prescribing patterns should be identified and avoided [4]. Rational use of drugs represents that patients receive drugs according to the clinical needs for an adequate time period and at the minimum cost. Misunderstanding over brand names, cost issue, unpredictable drugs supply, non-existence of formulary in hospitals and lack of knowledge by patients regarding dosing schedules are the major causes of irrational use of drugs [3] which may leads to inadequate therapeutic effects, undesirable drug event and adverse drug interactions [5-6]. Correct diagnosis, accurate prescribing, proper dispensing, appropriate packing and good patient counselling are the important criteria for rational use of drugs [3]. Also the use of multiple drugs not only facilitates the cost and regimens complication but also increases the incidence of undesirable drug reactions and drug interactions [1].

One of the major causes of death and morbidity throughout the world is a cardiovascular disease (CVD). According to the reports of World health Organization (WHO) 17.5 million patients in 2008 died from CVDs (Cardiovascular diseases) also it was reported that by 2015 approximately 20 million patients will die mainly due to heart disease [7]. The risk factors for CVDs are multiple such as elevated cholesterol and blood pressure levels, excessive smoking habits, diabetes, malnutrition and fatness etc [8]. Authors reported that different preventive actions have been taken by western countries which reduced the risk associated with the occurrence of CVDs [9].

Previously, the risk of CVDs was examined in different countries [10]. But the studies on outpatients in tertiary care setups particularly in Karachi, Pakistan are exceptional and incomplete. Authors reported that population based prescribing trends have significance impact on patient health [11]. In the present study we examined the prescribing trends among the outpatients visited to different tertiary care hospitals and also to assess the cost effectiveness of existing practice.

\section{Material and Methods}

Present cross-sectional study was conducted in various tertiary care setups located in various areas of Karachi, from January to March, 2014. We collected the data from 100 patients having different age groups. Data collection was based on prescriptions which were issued to them in which all the patients are identified by names, age, gender and other necessary information. Data were analyzed by Microsoft Excel $^{\mathrm{TM}}$.

\section{Results and Discussion}

The drug utilization study is conducting widely and it is being carried out in different health care setups. Such studies are helpful to determine the behaviour of the use of medicines in a society [2]. A survey based on prescription is considered to be one of the most cost

*Corresponding author: Naveed S, Jinnah University for Women, Karachi, Pakistan, Tel: 0300-2621917; E-mail: safila117@yahoo.com

Received October 25, 2014; Accepted January 02, 2014; Published January 06 2015

Citation: Zafar F, Ali H, Naveed S, Korai OU, Rizvi M, et al. (2015) Drug Utilization Pattern in Cardiovascular Diseases: A Descriptive Study in Tertiary Care Settings in Pakistan. J Bioequiv Availab 7: 059-062. doi:10.4172/jbb.1000215

Copyright: (c) 2015 Zafar F, et al. This is an open-access article distributed under the terms of the Creative Commons Attribution License, which permits unrestricted use, distribution, and reproduction in any medium, provided the original author and source are credited. 
effective methods to determine the prescribing approach of physicians [10]. Among adult population the first and third leading death reasons is the heart disease and stroke [12]. In the present study we collected the data of 100 patients. Results indicated that males (55\%) patients had a high frequency of cardiovascular incidences as compared to females (45\%) patients as shown in Figure 1. From 100 patients, $37 \%$ of patients (Male $25 \%$; Female $12 \%$ ) belongs to the age groups (30 $40 \mathrm{yrs}$ ), $43 \%$ of patients (Male $28 \%$; Female $15 \%$ ) belongs to the age groups (41-60 yrs) while $20 \%$ of patients (Male $11 \%$; Female $9 \%$ ) belongs to the age groups (61-90 yrs) as mentioned in Figure 2.

Out of 100 patients, $20 \%$ patients had Ischemic heart disease (IHD), hypertension (HTN) (31\%), Myocardial infarction (MI) (10\%) and Cardio Vascular Atherosclerosis (CVA) (10\%) as shown in Figure 3. We found that $35 \%$ patients were having disordered lipid profile. Doctor's also diagnosed various other associated medical conditions in number of patients i.e. $19 \%$ patients were having diabetes type -I, while (18\%) were having renal problems, also bronchial asthma was found in $2 \%$ patients. Scientists have reported that in United States approximately 74.5 million cases were related to hypertension, followed by 17.6 million and 6.4 million cases of coronary heart disease and stroke [13]. During the study different adjustable related risk factors were also determined which are associated with cardiovascular diseases particularly inadequate diet, physical inactivity, use of tobacco and abnormal blood lipid profile and obesity. Also other studies have indicated that high levels of insulin (frequently occurs in type II diabetes mellitus), is one of the independent factor related with cardiovascular disease [14].

Figure 4 indicated that $(10 \%)$ patients were prescribed with a single drug. Results showed that (66\%) patients were prescribed two drugs while $(23 \%)$ patients and ( $1 \%)$ patients were found to be prescribed with three and four medications respectively. Figure 5 showed the prescribing trend of different cardiovascular drugs. Results indicated that most commonly prescribed drugs were found to be Beta Blocker (52\%), Loop Diuretics (42\%), Calcium Channel Blocker (32\%), ACE

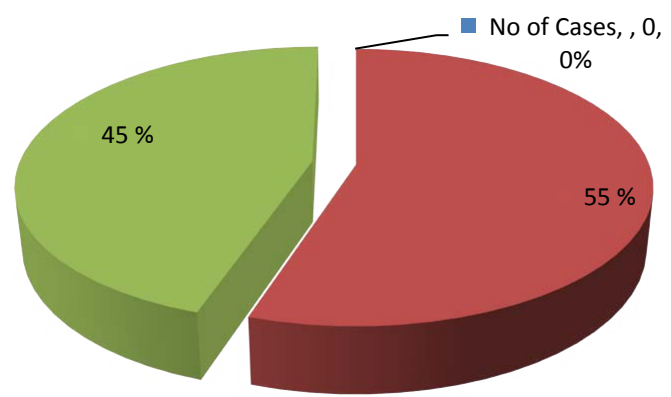

- Male

Female

Figure 1: Number of Male and Female Patients.

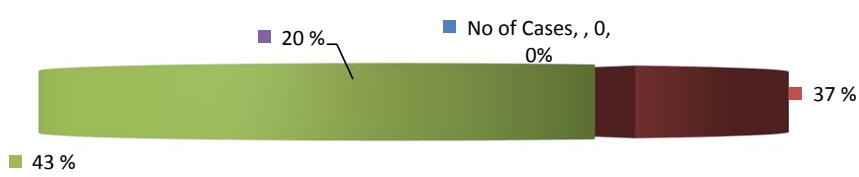

$\square 30-40 \mathrm{yrs}$

$\square 1-60 \mathrm{yrs}$ $\square 61-90 \mathrm{yrs}$

Figure 2: Age Groups of the patients.

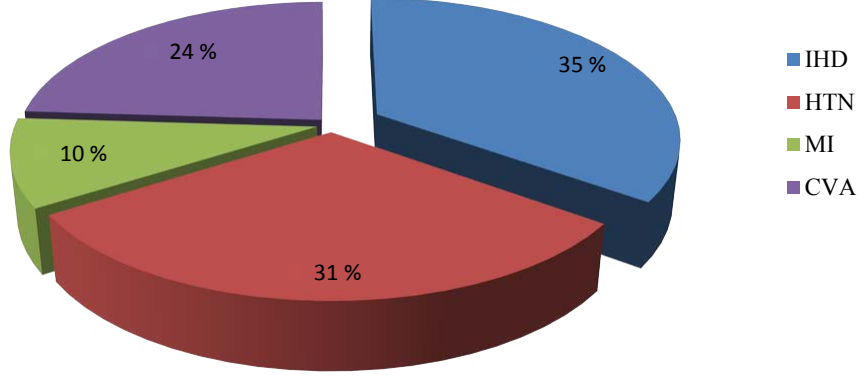

Figure 3: Percentages of different diseases found in patients.

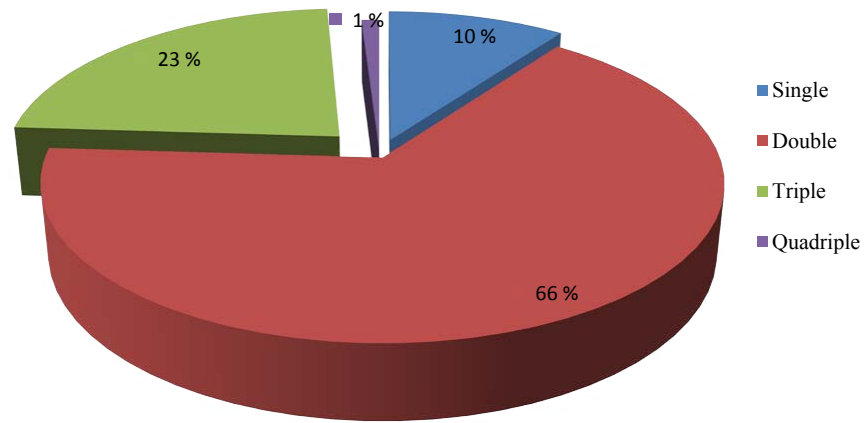

Figure 4: Percentages of drugs used alone in combinations.

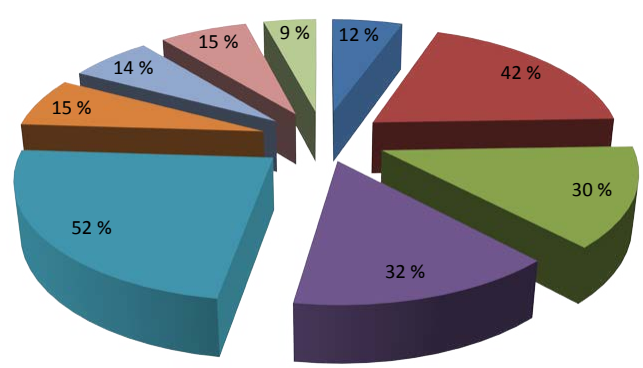

- Antianginal

- Diuretics

- ACE Inhibitors

- Calcium Channel

Blocker

Beta Blocker

- Vasorelaxant

- Cardiac Stimulant

- Antiplatelet

Anticoagulant

Figure 5: Prescribing Trend of Physician.

Inhibitors (30 \%) etc. Heaton et al. [15] determined that Beta-blockers decreases the mortality rate when prescribed for the prevention of myocardial infarction.

In this study we assessed different prescribing errors related to routes of adminstration, dosing frequency and prescribed dose. Authors reported that one of the common most types of medication errors is the medication dose errors (particularly fails to account for renal insufficiency), exclusion (either fails to prescribe the drug or to continue the treatment) [16]. Table 1 presented the irrational use of antihypertensive drugs, drugs used for the management of IHD, MI and CVA related to dosing frequency (3\%, $9 \%, 2 \%$ and $2 \%)$ and prescribed dose $(7 \%, 5 \%, 3 \%$ and $9 \%)$ respectively. Arute et al. [17] reported that during the study they found 17 types of errors in prescribing drugs used to manage cardiovascular diseases which were suggested 459 times by doctors in total 156 prescriptions. Irrational drug prescribing pattern indicate a very important health related problem and is considered to be a major challenge for doctors [18]. 
Citation: Zafar F, Ali H, Naveed S, Korai OU, Rizvi M, et al. (2015) Drug Utilization Pattern in Cardiovascular Diseases: A Descriptive Study in Tertiary Care Settings in Pakistan. J Bioequiv Availab 7: 059-062. doi:10.4172/jbb.1000215

\begin{tabular}{|c|c|c|c|c|c|}
\hline Prescribed & $\begin{array}{c}\text { Appropriateness and } \\
\text { Inappropriateness }\end{array}$ & Drugs used For HTN (\%) & $\begin{array}{c}\text { Drugs used for IHD } \\
\text { Management (\%) }\end{array}$ & $\begin{array}{c}\text { Drugs used for MI } \\
\text { Management (\%) }\end{array}$ & $\begin{array}{c}\text { Drugs used for CVA } \\
\text { Management (\%) }\end{array}$ \\
\hline \multirow{2}{*}{ Route of Adminstration } & Rational & 31 & 20 & 10 \\
\hline \multirow{2}{*}{ Dosing Frequency } & Irrational & Rational & 28 & 0 & 0 \\
\cline { 2 - 5 } & Irrational & 3 & 11 & 3 \\
\hline \multirow{2}{*}{ Prescribed Dose } & Rational & 27 & 9 & 2 \\
\hline
\end{tabular}

Table 1: Rational and Irrational used of Drugs used in HTN, IHD, MI and CVA.

\begin{tabular}{|c|c|c|c|c|c|}
\hline \multicolumn{6}{|c|}{ CHI-SQUARE TEST } \\
\hline \multicolumn{6}{|c|}{ Route of Administration * Dose } \\
\hline & Value & df & Asymp. Sig. (2-sided) & Exact Sig. (2-sided) & Exact Sig. (1-sided) \\
\hline Pearson Chi-Square & $0.644^{\mathrm{a}}$ & 1 & 0.422 & \multirow{4}{*}{1.000} & \multirow{4}{*}{0.576} \\
\hline Continuity Correction ${ }^{b}$ & 0.000 & 1 & 1.000 & & \\
\hline Likelihood Ratio & 1.111 & 1 & 0.292 & & \\
\hline Linear-by-Linear Association & 0.638 & 1 & 0.424 & & \\
\hline \multicolumn{6}{|c|}{ Frequency * Dose } \\
\hline Pearson Chi-Square & $3.290^{\mathrm{a}}$ & 1 & 0.070 & \multirow{4}{*}{0.108} & \multirow{4}{*}{0.059} \\
\hline Continuity Correction ${ }^{b}$ & 2.234 & 1 & 0.135 & & \\
\hline Likelihood Ratio & 4.117 & 1 & 0.042 & & \\
\hline Linear-by-Linear Association & 3.257 & 1 & 0.071 & & \\
\hline \multicolumn{6}{|c|}{ Route of Administration *Frequency } \\
\hline Pearson Chi-Square & $1.755^{\mathrm{a}}$ & 1 & 0.185 & \multirow{4}{*}{0.296} & \multirow{4}{*}{0.296} \\
\hline Continuity Correction ${ }^{b}$ & 0.123 & 1 & 0.726 & & \\
\hline Likelihood Ratio & 1.277 & 1 & 0.258 & & \\
\hline Linear-by-Linear Association & 1.738 & 1 & 0.187 & & \\
\hline
\end{tabular}

Table 2: Chi Square Test.

\begin{tabular}{|c|c|c|c|c|c|}
\hline \multicolumn{6}{|c|}{ Route of Administration vs. Dose } \\
\hline \multicolumn{2}{|c|}{ Symmetric Measures } & Value & Asymp. Std. Error ${ }^{a}$ & Approx. $\mathrm{T}^{\mathrm{b}}$ & Approx. Sig. \\
\hline Interval by Interval & Pearson's $\mathrm{R}$ & -0.080 & 0.029 & -0.797 & $0.427^{\circ}$ \\
\hline Ordinal by Ordinal & Spearman Correlation & -0.080 & 0.029 & -0.797 & $0.427^{c}$ \\
\hline \multicolumn{6}{|c|}{ Frequency vs. Dose } \\
\hline Interval by Interval & Pearson's R & -0.181 & 0.066 & -1.826 & $0.071^{c}$ \\
\hline Ordinal by Ordinal & Spearman Correlation & -0.181 & 0.066 & -1.826 & $0.071^{c}$ \\
\hline \multicolumn{6}{|c|}{ ROA vs. Frequency } \\
\hline Interval by Interval & Pearson's R & 0.132 & 0.142 & 1.323 & $0.189 c$ \\
\hline Ordinal by Ordinal & Spearman Correlation & 0.132 & 0.142 & 1.323 & $0.189 c$ \\
\hline
\end{tabular}

Table 3: Symmetric Measures of Different Variables Using Descriptive Analysis.

\begin{tabular}{|c|c|c|c|c|}
\hline \multirow{2}{*}{ Descriptive } & \multicolumn{2}{|c|}{ Mean } & Std. Deviation \\
\cline { 2 - 4 } & Statistic & Std. Error & Statistic \\
\hline Frequency & 1.1600 & 0.03685 & 0.36845 & 0.136 \\
\hline Dose & 1.2400 & 0.04292 & 0.42923 \\
\hline
\end{tabular}

Table 4: Descriptive Analysis of Frequency and Dose.

Rationality of prescriptions was also assessed using SPSS 20.0 by Chi- square test with $0.05 \%$ confidence Interval. This test was used to estimate the significant values of different factors including route of administration, dose and frequency in observed samples and numerous conditions were found significant (Table 2). Ordinal and interval symmetric measures were also assessed with Pearson's and Spearman Correlation for different factors (Table 3). Standard errors, standard deviations and variance were calculated for frequency and dose using descriptive analysis (Table 4). Irrational therapy is also due to the lack of rationalized and reliable drug information for the prescribers [19]. Figure 6 indicated the minimum and maximum cost of drugs mostly prescribed in cardiovascular diseases. Data showed the significantly high variation in the price of drug (per unit pack) that might be due to the fact that local manufacturer of pharmaceutical offer comparably low price in contrast to the cost of the drug manufactured by multinational industries. These costly articles may increase the economic burden on the patients which may intern affects the availability and the affordability of these life saving drugs especially in developing countries where health issues are in parallel concerns with the cost of the drug.

\section{Conclusion}

This study will indicate that irrational prescribing patterns in various conditions of cardiovascular diseases. In order to attain optimal results from the therapy unnecessary multifaceted prescription must be discouraged beside that modifications in lifestyle and preventing associated factors need to be suggested with the prescribed therapy. 
Citation: Zafar F, Ali H, Naveed S, Korai OU, Rizvi M, et al. (2015) Drug Utilization Pattern in Cardiovascular Diseases: A Descriptive Study in Tertiary Care Settings in Pakistan. J Bioequiv Availab 7: 059-062. doi:10.4172/jbb.1000215

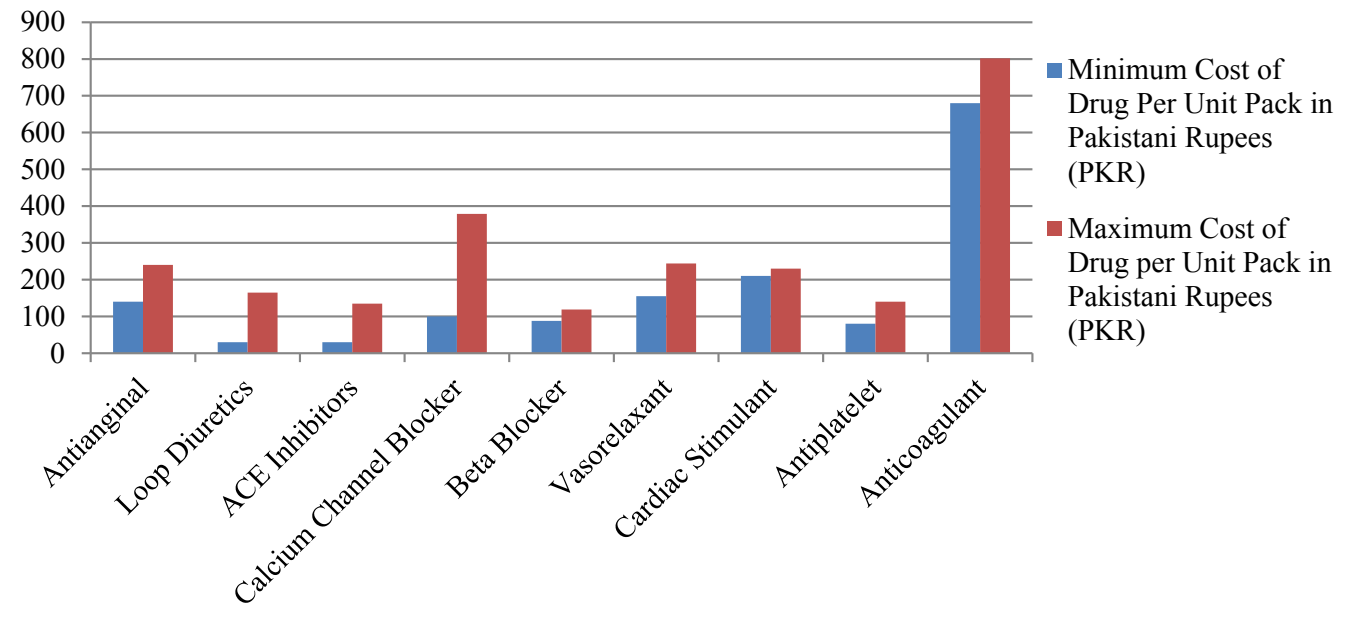

Figure 6: Minimum and Maximum Cost of Drugs mostly prescribed in Cardiovascular diseases.

\section{References}

1. Taskeen M, Anitha N, Ali SR, Bharath R, Khan AB (2012) A study on rational drug prescribing pattern in geriatric patients in hyderabad metropolitan. JDDTJ 2: 109-113.

2. Laporte JR, Baksaas I, Lunde PKM (1993) General background. In Dukes MNG (Edn) Drug utilization studies methods and uses, WHO regional publication. European series No.45 Copenhagen WHO.

3. Sreedevi K, Venkateswara Rao J, Fareedullah Md, Vijayakumar S (2011) A study on prescription pattern of statins in cardiovascular disease. Der Pharmacia Lettre, 3: 393-396.

4. Al-Junid SM, Ezat WPS, Surianti S (2007) Prescribing Patterns and Drug Cost Among Cardiovascular Patients in Hospital Universities Kebangsaan Malaysia. Med J Malaysia 62: 59-65.

5. WHO (1985) Rational use of drugs-Report of the Conferences of experts, Nairobi, Kenya 25-29 November, World Health Organization: 338

6. WHO (1994a) Guide to good prescribing: A Practical Manual World Health Organization Geneva.

7. Muhit MA, Rahman O, Raihan SZ, Asaduzzaman M, Akbar MA, et al. (2012) Cardiovascular disease prevalence and prescription patterns at a tertiary level hospital in Bangladesh. JAPS 2: 80-84.

8. Manjula DAS, Sriram S, Rajalingam B, Anthraper AR, Varghese RS, et al. (2012) Evaluation of the Rationality of Fixed Dose Combinations of Cardiovascular drugs in a Multispecialty Tertiary care hospital in Coimbatore, Tamilnadu, India. Hygeia. J D Med 4: 51-58.

9. Khonputsa $P$, Veerman LJ, Bertram M, Lim SS, Chaiyakunnaphruk N et al. (2012) Generalized Cost-Effectiveness Analysis of Pharmaceutical Interventions for Primary Prevention of Cardiovascular Disease in Thailand. ViHRI 1: 15-22.

10. Jankovic SM, Slavica M, Dukic DJ (2001) Drug utilization trends in clinical hospital centre "Kragujevac" from 1997-1999. Ind Jour Pharmacol 33: 29-36.

11. Psaty BM, Savage PJ, Tell GS, Polak JF, Hirsch CH, et al. (1993) Temporal patterns of antihypertensive medication use among elderly patients. JAMA 270: 1837-1841.
12. National Center for Health Statistics 2010 Health, United States (2009) With Special Feature on Medical Technology. Hyattsville.

13. Lloyd-Jones D, Adams RJ, Brown TM, Carnethon M, Dai S, et al. (2010) Heart disease and stroke statistics-2010 update. Circulation 121: e46-e215.

14. University of Montreal (2008) Depression and anxiety can double chances of heart ailments. Science Daily.

15. Everly MJ, Heaton PC, Cluxton RJ Jr (2004) Beta-blocker underused in secondary prevention of myocardial infarction. Ann Pharmacother 38: 286-293.

16. Rogers WJ, Bowlby LJ, Chandra NC, French WJ, Gore JM, et al. (1994) Treatment of myocardial infarction in the United States (1990 to 1993) observations from the National Registry of Myocardial Infarction. Circulation 90: 2103-2114.

17. JE Arute, PO Erah, UC Aguomo, EA Bamigbola (2011) Prescribing Errors in Cardiovascular Diseases in a Tertiary Health Care Facillty. Niger J Pharmaceut Res 9: 57-62.

18. Eze UI and Olowu AO (2011) Prescribing patterns and inappropriate use of medications in elderly outpatients in a tertiary hospital in Nigeria. TJPR 10: 19-25.

19. Pitt B, Segal R, Martinez FA, Meurers G, Cowley AJ, et al (1997) Randomized trials of losartan versus captopril in patients over 65 with heart failure. Lancent 349: 747-752. 